Supplement of Biogeosciences Discuss., 11, 13127-13156, 2014

http://www.biogeosciences-discuss.net/11/13127/2014/

doi:10.5194/bgd-11-13127-2014-supplement

(C) Author(s) 2014. CC Attribution 3.0 License.

(c) (i)

Supplement of

\title{
Nitrogen control of ${ }^{13} \mathrm{C}$ enrichment in heterotrophic organs relative to leaves in a landscape-building desert plant species
}

\section{J. Zhang et al.}

Correspondence to: L. Gu (lianhong-gu@ornl.gov), Q. Lu (luqi@caf.ac.cn), and P. Meng (mengping@caf.ac.cn) 


\section{Figure Caption}

35 Figure S1. Nutrient dependence of the difference in carbon isotope compositions between leaves and

36 heterotrophic organs of Nitraria tangutorum Bobrov, which is measured by $\Delta^{13} C_{\text {organ }}$ in Eq (1) and

37 averaged across the nebkhas excavated at the same study site. Negative values indicate ${ }^{13} \mathrm{C}$

38 enrichment in heterotrophic organs compared to leaves. Changes of $\Delta^{13} C_{\text {organ }}$ as a function of organ

39 contents of carbon (a), nitrogen (b) and phosphorous (c) and of organ ratios of carbon to nitrogen (d),

40 nitrogen to phosphorous (e), and carbon to phosphorus (f). The two arrows in (b) indicate values for

41 woody debris from dead ramets at each study site while in (d) indicates an outlier caused by

42 measurements in phosphorous content (see the outlier in $\mathrm{c}$ and $\mathrm{f}$ ). All nutrient values are normalized

43 (divided) by their corresponding values in the leaves.
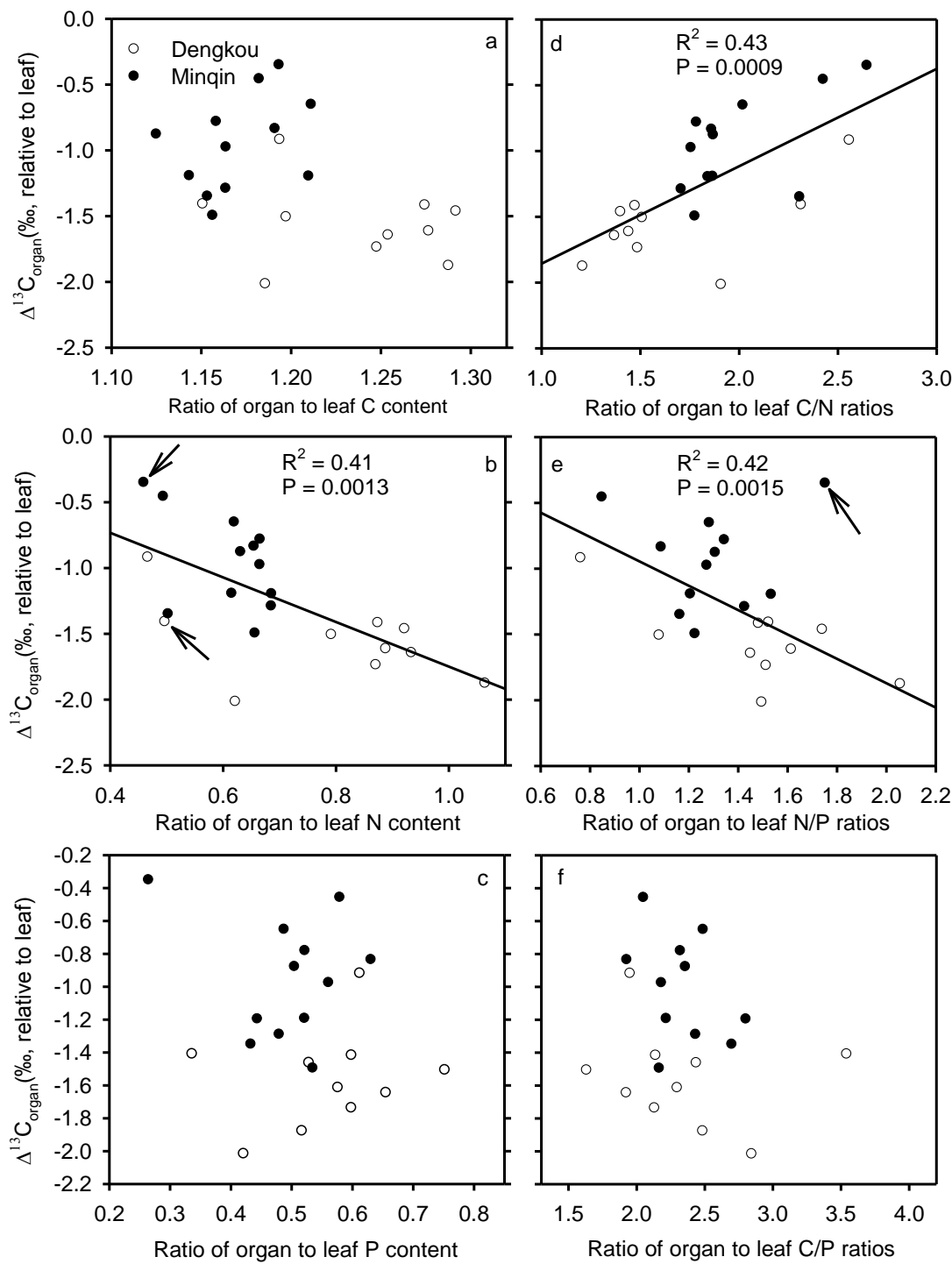